\title{
Capacity and Hypoxic Response of Subcutaneous Adipose Tissue Blood Flow in Humans
}

\author{
Ilkka Heinonen, PhD; Jukka Kemppainen, MD, PhD; Kimmo Kaskinoro, MD; \\ Juhani Knuuti, MD, PhD; Robert Boushel, PhD; Kari K. Kalliokoski, PhD
}

\begin{abstract}
Background: The blood flow capacity in subcutaneous adipose tissue in humans remains largely unknown, and therefore the aim of this study was to determine the physiological range of blood flow in this tissue.

Methods and Results: The subcutaneous adipose tissue blood flow (ATBF) was measured in 9 healthy young men by positron emission tomography using radiowater tracer. Subcutaneous ATBF was determined in regions adjacent to knee extensors at rest and during dynamic knee extensor exercise, and with 2 physiological perturbations: while breathing moderate systemic hypoxic air $\left(14 \% \mathrm{O}_{2}\right)$ at rest and during exercise, and during intra-femoral artery infusion of high-dose adenosine infusion. ATBF was $1.3 \pm 0.6 \mathrm{ml} \cdot 100 \mathrm{~g}^{-1} \cdot \mathrm{min}^{-1}$ at rest and increased with exercise $\left(8.0 \pm 3.0 \mathrm{ml} \cdot 100 \mathrm{~g}^{-1} \cdot \mathrm{min}^{-1}, \mathrm{P}<0.001\right)$ and adenosine infusion $\left(10.5 \pm 4.9 \mathrm{ml} \cdot 100 \mathrm{~g}^{-1} \cdot \mathrm{min}^{-1}, \mathrm{P}=0.001\right)$, but not when breathing moderate systemic hypoxic air $\left(1.5 \pm 0.4 \mathrm{ml} \cdot 100 \mathrm{~g}^{-1} \cdot \mathrm{min}^{-1}\right)$. ATBF was similar during exercise and adenosine infusion, but vascular conductance was lower during adenosine infusion. Finally, ATBF during exercise in moderate systemic hypoxia was reduced $\left(6.3 \pm 2.2 \mathrm{ml} \cdot 100 \mathrm{~g}^{-1} \cdot \mathrm{min}^{-1}\right)$ compared to normoxic exercise $(P=0.004)$.
\end{abstract}

Conclusions: The vasodilatation capacity of human subcutaneous adipose blood flow appears to be comparable to, or even higher, than that induced by moderate intensity exercise. Furthermore, the reduced blood flow response in subcutaneous adipose tissue during systemic hypoxia is likely to contribute, in part, to the redistribution of blood flow to exercising muscle in a condition of reduced oxygen availability. (Circ $J$ 2014; 78: 1501-1506)

Key Words: Adipose tissue; Blood flow; Capacity; Human; Hypoxia

A dipose tissue plays an important role in controlling metabolism in the human body, ${ }^{1-3}$ and the circulation to adipose tissue is an integral part of its metabolic and endocrine function. ${ }^{4,5}$ Despite the fact that adipose tissue has a capillary surface area less than one-third that in skeletal muscle, ${ }^{5}$ it has long been acknowledged that adipocytes are surrounded by an extensive network of capillaries. ${ }^{4}$ This circulatory feature importantly affects the adaptability of subcutaneous adipose tissue to excess caloric overload, which is, in contrast, also associated with a hypoxic state in adipose tissue. ${ }^{1,6}$ While chronic hypoxia in expanded adipose tissue is now well known to lead to metabolic disturbances due to the insufficient blood supply, ${ }^{1,6}$ the effects of acute environmentally induced hypoxia on adipose blood flow in both lean healthy humans and patients with cardiovascular, respiratory and metabolic diseases needs further clarification. ${ }^{1-3,7-9}$ Along these lines, in the present study, we measured the capacity and hypoxic response of adipose blood flow in 9 healthy young men by positron emis- sion tomography. Blood flow capacity was determined by direct intra-femoral infusion of adenosine, with a dose that has previously been shown to induce maximal thigh blood flow. ${ }^{10}$ The hypoxic response was elucidated by letting subjects breathe moderate systemic hypoxic air $\left(14 \% \mathrm{O}_{2}\right)$ at rest and during exercise. It was hypothesised that the blood flow capacity of adipose tissue is at least comparable, or even higher, than that induced by moderate intensity exercise. We also expected a higher adipose tissue blood flow in response to hypoxia at rest, but a lower blood flow during exercise, compared to the respective normoxic conditions.

\section{Subjects}

Nine healthy young men $(25 \pm 5$ years, $184 \pm 6 \mathrm{~cm}, 76 \pm 9 \mathrm{~kg})$ volunteered to participate in the study. The purpose, nature, and potential risks of the study were explained to the subjects be-

Received October 14, 2013; revised manuscript received February 19, 2014; accepted February 20, 2014; released online April 22, 2014 Time for primary review: 17 days

Turku PET Centre (I.H., J. Kemppainen, J. Knuuti, K.K.K.), Research Centre of Applied and Preventive Cardiovascular Medicine (I.H.), Department of Anaesthesiology (K. Kaskinoro), Department of Clinical Physiology and Nuclear Medicine (J. Kemppainen), University of Turku and Turku University Hospital, Turku, Finland; Åstrand Laboratory, The Swedish School of Sport and Health Sciences, Stockholm (R.B.), Sweden; and Division of Experimental Cardiology, Thoraxcenter, Erasmus MC, University Medical Center Rotterdam, Rotterdam (I.H.), The Netherlands

Mailing address: Ilkka Heinonen, Turku PET Centre, PO Box 52, FIN-20521 Turku, Finland. E-mail: ilkka.heinonen@utu.fi

ISSN-1346-9843 doi:10.1253/circj.CJ-13-1273

All rights are reserved to the Japanese Circulation Society. For permissions, please e-mail: cj@j-circ.or.jp 


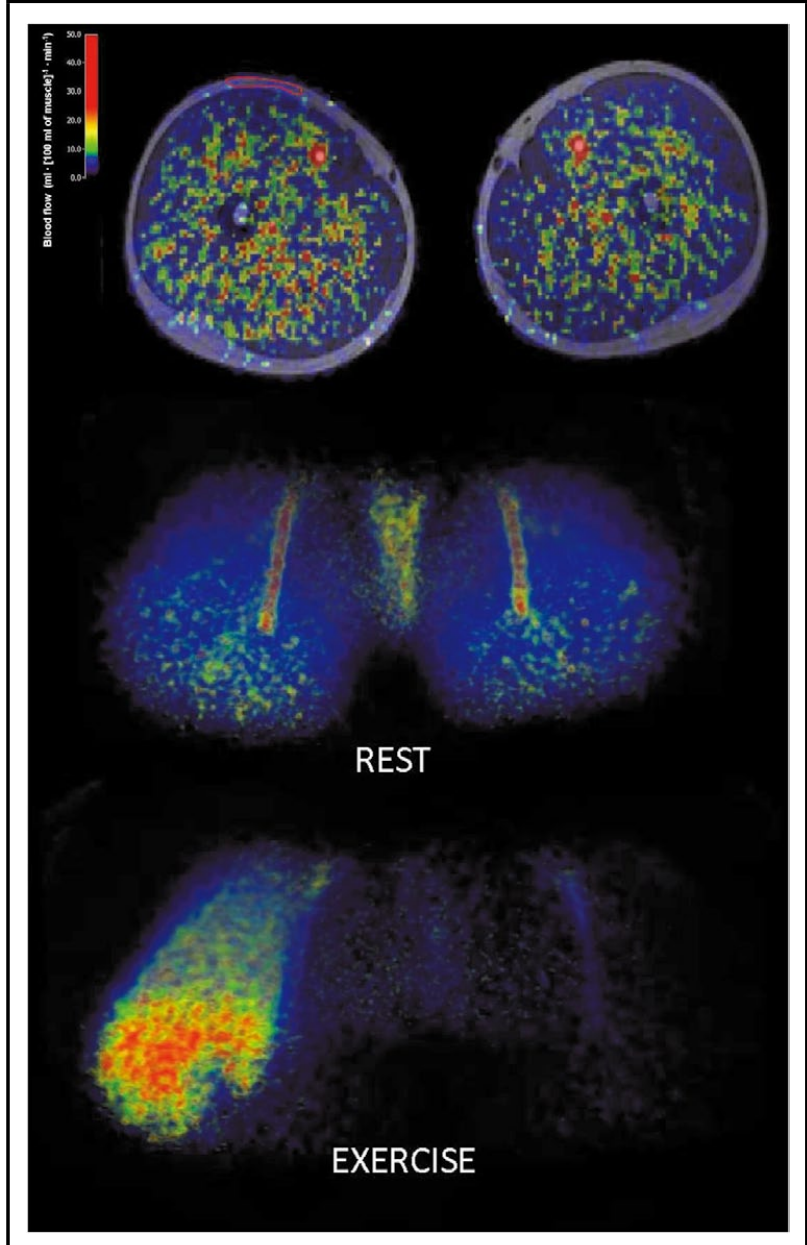

Figure 1. (A) Two-dimensional (2D) positron emission tomography (PET) blood flow and MRI fusion image in the middle thigh region where the region of interest for adipose tissue analyses is also illustrated. (B) Three-dimensional (3D) PET blood flow image in the thigh region under resting baseline conditions. (C) Three-dimensional (3D) PET blood flow image in the thigh region during exercise.

fore they gave their written informed consent to participate. The subjects were requested to abstain from caffeine-containing beverages for at least $24 \mathrm{~h}$ before the experiments, as well as to avoid strenuous exercise within $48 \mathrm{~h}$ prior to the study. The subjects were not taking any regular medication. The study was performed at least $4 \mathrm{~h}$ after the subjects had eaten a light breakfast. The study was performed according to the Declaration of Helsinki and was approved by the Ethics Committee of the Intermunicipal Hospital District of Southwest Finland and the National Agency for Medicines.

\section{Study Design}

Subcutaneous adipose tissue blood flow (ATBF) in the femoral region was measured using positron emission tomography (PET) with $\left[{ }^{15} \mathrm{O}\right]-\mathrm{H}_{2} \mathrm{O}$, as described in detail previously ${ }^{11,12}$ and briefly below, and in Figure 1. ATBF was measured first under normal resting conditions and then either during systemic hypoxia (14\% inspired $\mathrm{O}_{2}$ in $\mathrm{N}_{2}$; equivalent to am altitude of $\sim 3,400 \mathrm{~m}$ ) or local adenosine infusion. The order of hypoxia and adenosine measurements was randomized. After these measurements at rest, blood flow was measured during dynamic 1-leg exercise in a counterbalanced setting with the subject breathing either normal room air or hypoxic gas. Additionally, blood samples were drawn from the radial artery for blood gas analyses in the middle of each study occasion mentioned above. Exercise consisted of dynamic 1-leg exercise at $40 \mathrm{rpm}$ with individually chosen workloads $(4.3 \pm 2.1 \mathrm{~kg})$ with a knee angle range of motion of $~ 70-80$ degrees. During pre-testing before the actual experiments, individually appropriate workloads for each subject were chosen so that they could exercise for at least $\sim 10$ min without fatigue or discomfort. Exercise was estimated to represent $\sim 10$ watts of an external 1-leg knee extension workload.

\section{Other Procedures Before and After PET Measurements}

Before the PET experiments, the antecubital vein was cannulated for tracer administration. For blood sampling, a radial artery cannula was placed under local anesthesia in the contralateral arm. Additionally, cannulas were placed under local anesthesia into the femoral artery and vein for local adenosine infusion and blood sampling, respectively. Subjects were then moved to the PET scanner with the femoral region in the gantry and the right leg was fastened to a custom-designed dynamometer.

\section{Blood Flow Measurements and Analysis}

Radiowater positron-emitting tracer $\left[{ }^{15} \mathrm{O}\right]-\mathrm{H}_{2} \mathrm{O}$ was produced, as previously described in detail, ${ }^{13}$ and the ECAT EXACT HR+ scanner (Siemens/CTI, Knoxville, TN, USA) was used in $3 \mathrm{D}$ mode for image acquisition to measure ATBF. Photon attenuation was corrected by 5 -min transmission scans performed both at the beginning of the resting and exercise PET studies. All data were corrected for dead time, decay and measured photon attenuation. During systemic hypoxia, breathing air with $14 \%$ oxygen gas began 5 min before imaging. Femoral arterial infusion of adenosine was initiated $1 \mathrm{~min}$ before the PET scanning and continued until the end of the scan (6min in total). The adenosine concentration $\left(1 \mathrm{mg} \cdot \mathrm{min}^{-1} \cdot \mathrm{L}\right.$ thigh volume $\left.{ }^{-1}\right)$ was based on the study by Rådegran and Calbet ${ }^{10}$ at rest and Barden et $\mathrm{al}^{14}$ during maximal exercise. This concentration has been shown to induce maximal femoral artery blood flow, as measured with ultrasound Doppler, and thus a maximal stimulus for ATBF was also expected. During exercise, scanning commenced $3 \mathrm{~min}$ after exercise onset to obtain a metabolic steady-state situation and was continued until the end of the exercise bout, which every time lasted an additional $2.5 \mathrm{~min}$. Thus, the exercise duration was $5.5 \mathrm{~min}$. Arterial blood radioactivity was also sampled continuously with a detector during imaging for blood flow quantification. Data analysis was performed using the standard models and methods. ${ }^{15,16}$ In addition to ATBF, muscle blood flow was also measured for comparison, as described and reported previously. ${ }^{17,18}$

\section{Other Measurements and Analysis}

Structural magnetic resonance imaging (MRI) of the experimental thigh was performed to be combined with PET blood flow images for precise adipose tissue localisation (Figure 1), as previously described.${ }^{17}$ Arterial oxygen was analyzed with a Radiometer ABL 835 blood gas analyzer.

\section{Statistical Analysis}

Statistical analyses were performed with SAS 9.2 version (SAS Institute, Cary, NC) using an ANOVA. If a significant main effect(s) was found, pairwise differences were identified using the Tukey-Kramer post hoc test. Relationships between variables were investigated by using Pearson correlation coeffi- 


\begin{tabular}{|c|c|c|c|c|c|}
\hline \multirow{2}{*}{ Physiological variables } & \multicolumn{3}{|c|}{ Rest } & \multicolumn{2}{|c|}{ Exercise } \\
\hline & Baseline & Hypoxia & Adenosine & Normoxia & Hypoxia \\
\hline Heart rate $(\mathrm{bpm})$ & $61 \pm 10$ & $69 \pm 10^{* *}$ & $78 \pm 9^{\dagger}$ & $92 \pm 12$ & $102 \pm 10 \S$ \\
\hline Mean arterial pressure $(\mathrm{mmHg})$ & $91 \pm 7$ & $98 \pm 12$ & $95 \pm 8$ & $108 \pm 6$ & $112 \pm 10$ \\
\hline Systolic blood pressure $(\mathrm{mmHg})$ & $125 \pm 9$ & $137 \pm 18$ & $133 \pm 11$ & $146 \pm 7$ & $152 \pm 11$ \\
\hline Diastolic blood pressure $(\mathrm{mmHg})$ & $74 \pm 6$ & $79 \pm 10$ & $76 \pm 7$ & $90 \pm 9$ & $92 \pm 12$ \\
\hline Arterial oxygen saturation (\%) & $98 \pm 1$ & $91 \pm 5^{\star \star}$ & $98 \pm 1$ & $98 \pm 1$ & $88 \pm 5 \S \S$ \\
\hline Arterial oxygen content (ml/L) & $199 \pm 9$ & $186 \pm 13^{* *}$ & $202 \pm 7$ & $205 \pm 9$ & $182 \pm 11 \S \S \S$ \\
\hline
\end{tabular}

Comparisons at rest: ${ }^{* *} \mathrm{P}<0.01$ compared to baseline and adenosine, ${ }^{\dagger} \mathrm{P}<0.05$ compared to both baseline and hypoxia.

Comparisons during exercise: ${ }^{\mathrm{P}}<0.05,{ }^{\S} \mathrm{P}<0.01,{ }^{\S \S} \mathrm{P}<0.001$ compared to normoxia.
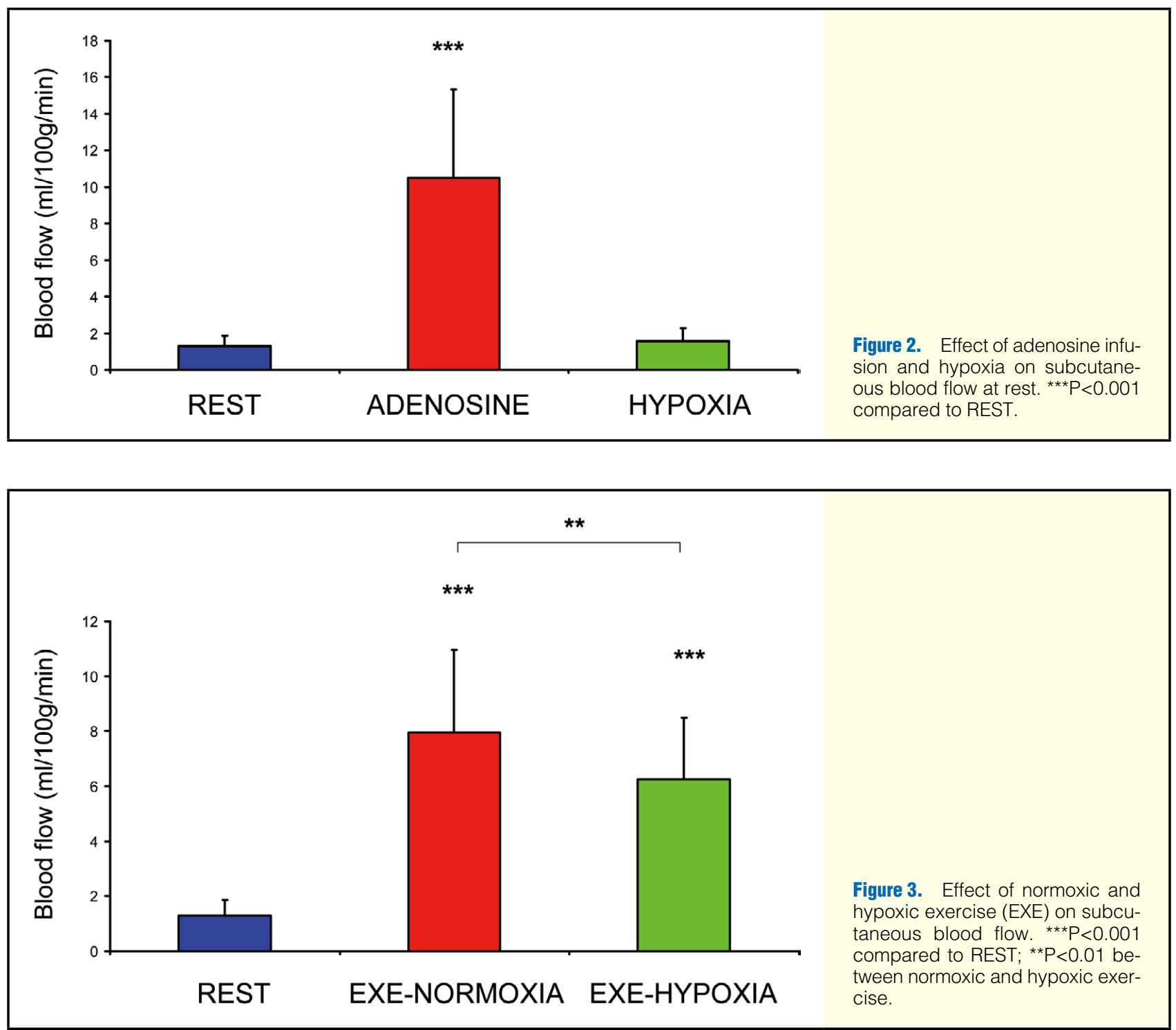

cient. Results are expressed as mean $\pm \mathrm{SD}$ and $\mathrm{P} \leq 0.05$ was considered statistically significant.

\section{Results}

The general cardiovascular responses to the studied physiolog- ical perturbations and exercise are shown in Table. Heart rate increased in response to both adenosine and hypoxia at rest, but blood pressure remained unchanged from baseline. Directly determined arterial oxygen saturation and content decreased from baseline in response to hypoxia, and further reductions were observed during hypoxic exercise compared to normox- 


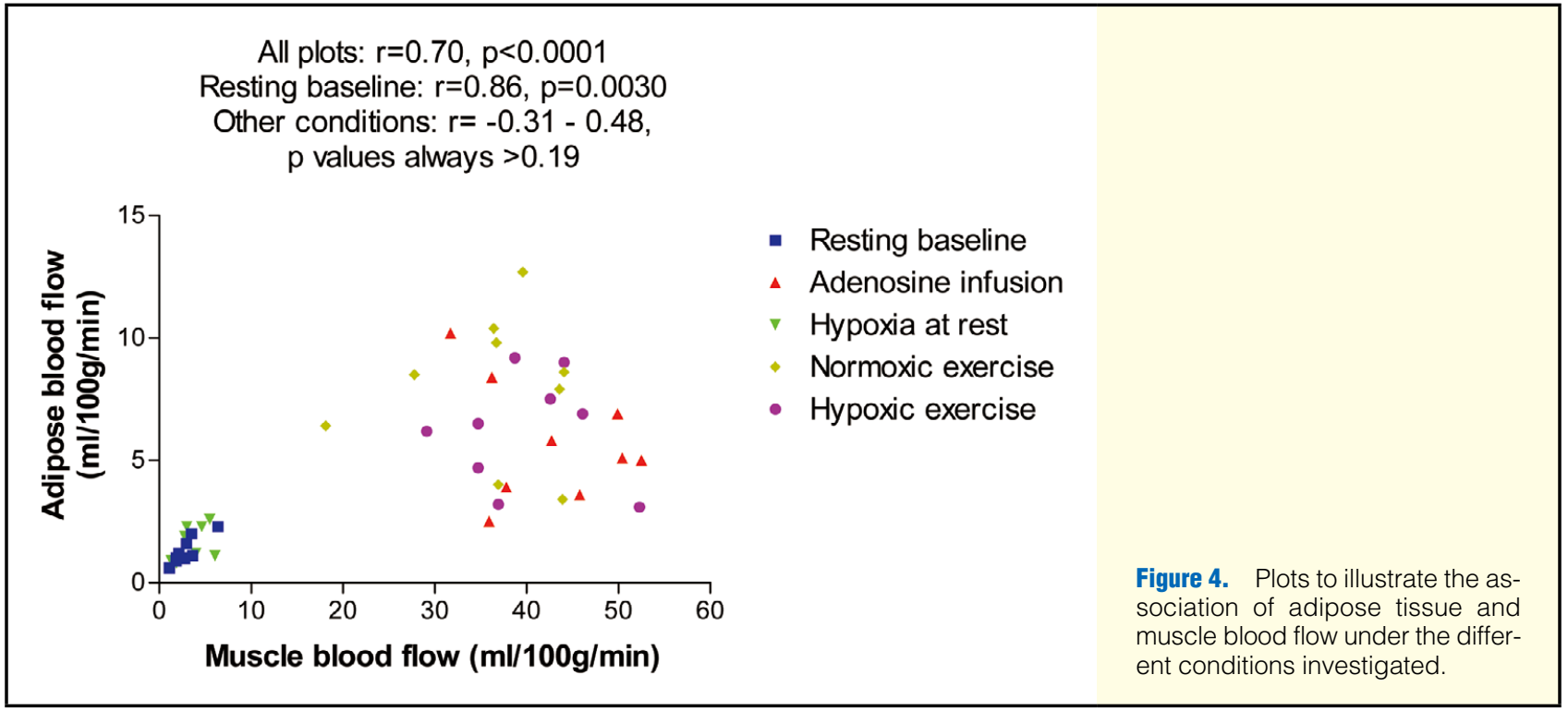

ic exercise. Similarly, compared to at rest, the heart rate was increased but the blood pressure was similar during hypoxia compared to normoxia during exercise.

Adipose tissue blood flow was $1.3 \pm 0.6 \mathrm{ml} \cdot 100 \mathrm{~g}^{-1} \cdot \mathrm{min}^{-1}$ at rest and was increased by adenosine infusion (Figure 2 ) and exercise (Figure 3), but not by breathing in moderate systemic hypoxic air (Figure 2). ATBF was similar during exercise and adenosine infusion $(\mathrm{P}=0.23)$. ATBF during exercise in moderate systemic hypoxia was reduced compared to during normoxic exercise (Figure 3, $\mathrm{P}=0.004$ ).

At rest, adipose vascular conductance was elevated from rest $\left(0.014 \pm 0.005 \mathrm{ml} \cdot 100 \mathrm{~g}^{-1} \cdot \mathrm{min}^{-1} \cdot \mathrm{mmHg}^{-1}\right)$ to adenosine infusion $\left(0.118 \pm 0.058 \mathrm{ml} \cdot 100 \mathrm{~g}^{-1} \cdot \mathrm{min}^{-1} \cdot \mathrm{mmHg}^{-1} ; \mathrm{P}=0.001\right)$, but not during hypoxic air breathing $\left(0.016 \pm 0.005 \mathrm{ml} \cdot 100 \mathrm{~g}^{-1}\right.$. $\left.\mathrm{min}^{-1} \cdot \mathrm{mmHg}^{-1}\right)$. Adipose vascular conductance was also elevated from rest by exercise $\left(0.073 \pm 0.026 \mathrm{ml} \cdot 100 \mathrm{~g}^{-1} \cdot \mathrm{min}^{-1}\right.$. $\mathrm{mmHg}^{-1}, \mathrm{P}<0.0001$ ), although the mean arterial blood pressure was also enhanced from rest in response to the applied dynamic exercise (Table, $\mathrm{P}<0.001)$. Vascular conductance was higher during adenosine infusion compared to exercise $(\mathrm{P}<0.05)$. Finally, vascular conductance was lower during hypoxic $\left(0.056 \pm 0.022 \mathrm{ml} \cdot 100 \mathrm{~g}^{-1} \cdot \mathrm{min}^{-1} \cdot \mathrm{mmHg}^{-1}\right)$ compared to normoxic exercise $(\mathrm{P}=0.005)$.

Finally, adipose tissue blood flow correlated significantly with muscle blood flow at resting baseline, but not under any other conditions (Figure 4).

\section{Discussion}

The capacity and hypoxic response of blood flow in human subcutaneous adipose tissue remains incompletely understood. We show in the present study that the vasodilatation capacity of human subcutaneous adipose blood flow appears to be at least comparable to, or even higher, than that induced physiologically by moderate intensity exercise. In contrast, acute exposure to moderate systemic hypoxic air did not affect adipose tissue blood flow at rest, but during exercise, it was significantly reduced by systemic hypoxia compared to respective normoxic exercise.

White adipose tissue is known to be a highly responsive tissue to hypoxia, as exposure of adipocytes to reduced oxygen availability in cell culture changes the expression of over 1,000 genes. ${ }^{6}$ In the present study, no change was observed in subcutaneous adipose tissue blood flow in response to moderate systemic hypoxia at rest. As it appears that adipose blood flow in humans is under the direct control of the sympathetic nervous system, ${ }^{19}$ it is likely that in our study, hypoxia did not create a sufficiently high stimulus for sympathetic neural vasoconstriction activation to reduce blood flow. In contrast, the finding also suggests that stimulation of vasoconstriction by arterial chemoreceptors predominates over a local hypoxic vasodilation in adipose tissue in humans. In this regard, adipose tissue possesses similar features as bone, ${ }^{20}$ while increases in blood flow in response to systemic hypoxia have been reported in human skin. ${ }^{21}$ Further studies are warranted to investigate whether unchanged blood flow is of importance to explain the pathophysiological features of adipose tissue function under chronically low oxygen supply that is not compensated by higher blood flow. ${ }^{1,6}$ These conditions include, but are not limited to obesity, diabetes and cardiorespiratory disease, which are known or speculated to be associated with impaired adipose tissue function. ${ }^{1-3,7-9}$

In contrast to rest, subcutaneous adipose blood flow was reduced during exercise when subjects were breathing hypoxic air. This novel finding is likely based on the constriction of adipose tissue arterioles by hypoxia-induced increased sympathetic nervous activity, which redistributes limb blood flow to exercising muscles that are more critically dependent on adequate oxygen delivery during exercise. We have previously reported that adipose tissue blood flow is reduced by the acute local infusion of norepinehrine, the principal neurotransmitter released from sympathetic nerve endings, and that the inhibition of $\alpha$-adrenergic receptors by phetolamine tends to increase adipose blood flow, both at rest and during exercise. ${ }^{19}$ Romijn et al have also previously suggested that the reduction of adipose tissue blood flow could be one mechanism to explain decreased free-fatty acid release in response to high-intensity exercise, ${ }^{22}$ leading to preferential utilization of glucose and increased efficiency of ATP generation for a limited $\mathrm{O}_{2}$ availability. Similarly, Layden et al have proposed that reduced adipose tissue blood flow might be one mechanism to explain reduced lipolysis and/or mobilization during exercise in cold 
temperatures. ${ }^{23}$ Furthermore, it has been recently reported that the inability to increase adipose tissue vascular resistance during exercise or maintain mean arterial pressure during orthostatic stress with old age is largely a result of diminished $\alpha$-adrenergic responsiveness of adipose tissue arterioles. ${ }^{24,25}$ Hence, reduced adipose tissue blood flow is one potential acute physiological adjustment in response to short-term and/or highintensity exercise. Accordingly, our results indicate that part of the redistribution of blood flow towards exercising muscle in hypoxia ${ }^{18}$ involves vasoconstriction of adipose tissue, while increased adipose blood flow is required in response to prolonged exercise that also associates with increased lipolysis to provide free-fatty acids for muscular work. ${ }^{26}$ Mechanistically, the possibility remains that in addition to sympathetic nervous system influence, reduced oxygen content also directly contributed to reduced adipose blood flow as hypoxia, per se, is known to constrict arteries. ${ }^{27,28}$ It would be of interest to investigate whether adipose tissue blood flow changes in normoxic exercise below and above aerobic threshold, but unfortunately this threshold does not occur physiologically in incremental exercise to maximum in this well-established 1-leg knee extension model used in this study.

In addition to the hypoxic response, the peak blood flow capacity of human subcutaneous adipose tissue has remained largely unexplored. In this regard, our main novel finding is that the vasodilatation capacity of human subcutaneous adipose blood flow approximates the physiological level reached during moderate-intensity exercise. Vascular conductance can reach a level even higher than that induced by exercise. In terms of absolute values, the comparison of adipose tissue blood flow capacity to skeletal muscle is of interest. We have previously reported that blood flow in skeletal muscle during a similar adenosine infusion protocol, reaches a level of $40 \mathrm{ml} \cdot \mathrm{min}^{-1} \cdot 100 \mathrm{~g}^{-1} \cdot{ }^{17}$ As the mean value of adenosine-induced adipose blood flow was $10.5 \mathrm{ml} \cdot \mathrm{min}^{-1} \cdot 100 \mathrm{~g}^{-1}$, it represents $\sim 26 \%$ of that in muscle. In this light, the functional vascular capacity appears to closely follow that of structural anatomy, as adipose tissue has a capillary surface area that is slightly less than one-third than that of skeletal muscle. ${ }^{5}$ In terms of fold-increase from rest to adenosine, the percentage is even higher; $57 \%$, as adipose blood flow increased 8-fold and muscle blood flow increased 14-fold. In contrast to skeletal muscle, ${ }^{17}$ adenosine-induced blood flow was not, however, positively related to subjects' whole body maximal oxygen consumption (data not shown), meaning also that adipose and muscle blood flow do not simply parallel each other under most physiological conditions, although they closely correlate at resting baseline (Figure 4). The data nevertheless suggest that the functional blood flow capacity is quite large in healthy human subjects. It, however, needs to be determined if this capacity is lost in pathological states, and if a loss of functional vascular capacity associates with an impaired ability to store fats in white adipose tissue that contributes to metabolic and cardiovascular derangements in the human body. ${ }^{1}$ These investigations would be timely and highly relevant as obesity and diabetes, in particular, have become increasingly prevalent, and impairments in adipose tissue blood flow capacity could possibly contribute to explain other functional impairments of adipose tissue in patients. ${ }^{1-3,7-9}$

In conclusion, the vasodilatory capacity of human subcutaneous adipose blood flow appears to be at least comparable to that induced by moderate intensity exercise, and is some onethird of that in skeletal muscle. Acute breathing of moderate systemic hypoxic air does not affect adipose tissue blood flow at rest, but during exercise, systemic hypoxia reduces blood flow in subcutaneous adipose tissue and might serve as a mechanism to redistribute blood flow from inactive tissues to exercising skeletal muscle. Further mechanistic studies are warranted to investigate whether these reported responses are impaired in patients with cardiovascular and metabolic diseases, as could be hypothesized based on the known other impairments of adipose tissue function. It would also be worth determining whether exercise training, which maintains or even increases whole body fitness, could also improve the circulatory and functions of adipose tissue. ${ }^{29}$

\section{Acknowledgments}

The study was conducted within the Centre of Excellence in Molecular Imaging in Cardiovascular and Metabolic Research; this was supported by the Academy of Finland, University of Turku, Turku University Hospital, and Abo Academy.

This study could not have been performed without the contribution of the personnel of the Turku PET Centre and the authors want to thank them for their excellent assistance during the study. The authors also thank the subjects who participated.

The present study was financially supported by The Ministry of Education of the State of Finland, Academy of Finland, The Finnish Cultural Foundation and its South-Western Fund, The Finnish Sport Research Foundation, and Turku University Hospital (EVO funding).

\section{References}

1. Sun K, Kusminski CM, Scherer PE. Adipose tissue remodeling and obesity. J Clin Invest 2011; 121: 2094-2101.

2. Tchernof A, Despres JP. Pathophysiology of human visceral obesity: An update. Physiol Rev 2013; 93: 359-404.

3. Feng B, Zhang T, Xu H. Human adipose dynamics and metabolic health. Ann N Y Acad Sci 2013; 1281: 160-177.

4. Rosell S, Belfrage E. Blood circulation in adipose tissue. Physiol Rev 1979; 59: 1078-1104.

5. Roddie IC. Circulation to skin and adipose tissue. In: Shepherd JT, editor. Handbook of Physiology. The Cardiovascular system III edn. Bethesda, MD: American Physiological Society, 1983; 285-317.

6. Trayhurn P. Hypoxia and adipose tissue function and dysfunction in obesity. Physiol Rev 2013; 93: 1-21.

7. Chang L, Milton H, Eitzman DT, Chen YE. Paradoxical roles of perivascular adipose tissue in atherosclerosis and hypertension. Circ J 2013; 77: 11-18.

8. Yamashita K, Kondo T, Osugi S, Shimokata K, Maeda K, Okumura $\mathrm{N}$, et al. The significance of measuring body fat percentage determined by bioelectrical impedance analysis for detecting subjects with cardiovascular disease risk factors. Circ J 2012; 76: 2435-2442.

9. Kunita E, Yamamoto H, Kitagawa T, Ohashi N, Utsunomiya H, Oka $\mathrm{T}$, et al. Association between plasma high-molecular-weight adiponectin and coronary plaque characteristics assessed by computed tomography angiography in conditions of visceral adipose accumulation. Circ J 2012; 76: 1687-1696.

10. Rådegran G, Calbet JA. Role of adenosine in exercise-induced human skeletal muscle vasodilatation. Acta Physiol Scand 2001; 171: 177 185.

11. Heinonen I, Bucci M, Kemppainen J, Knuuti J, Nuutila P, Boushel $\mathrm{R}$, et al. Regulation of subcutaneous adipose tissue blood flow during exercise in humans. J Appl Physiol 2012; 112: 1059-1063.

12. Heinonen I, Saltin B, Kemppainen J, Sipilä HT, Oikonen V, Nuutila $\mathrm{P}$, et al. Skeletal muscle blood flow and oxygen uptake at rest and during exercise in humans: A pet study with nitric oxide and cyclooxygenase inhibition. Am J Physiol Heart Circ Physiol 2011; 300: H1510-H1517.

13. Sipilä HT, Clark JC, Peltola O, Teräs M. An automatic $\left[{ }^{15} \mathrm{O}\right]-\mathrm{H}_{2} \mathrm{O}$ production system for heart and brain studies. J Label Compd Radiopharm 2001; 44(Suppl1): S1066-S1068.

14. Barden J, Lawrenson L, Poole JG, Kim J, Wray DW, Bailey DM, et al. Limitations to vasodilatory capacity and . $\mathrm{VO} 2$ max in trained human skeletal muscle. Am J Physiol Heart Circ Physiol 2007; 292: $\mathrm{H} 2491-\mathrm{H} 2497$.

15. Iida H, Kanno I, Miura S, Murakami M, Takahashi K, Uemura K. Error analysis of a quantitative cerebral blood flow measurement using $\mathrm{H} 2(15) \mathrm{O}$ autoradiography and positron emission tomography, with respect to the dispersion of the input function. J Cereb Blood Flow Metab 1986; 6: 536-545.

16. Ruotsalainen U, Raitakari M, Nuutila $P$, Oikonen V, Sipilä H, Teräs M, et al. Quantitative blood flow measurement of skeletal muscle 
using oxygen-15- water and PET. J Nucl Med 1997; 38: 314-319.

17. Heinonen I, Kemppainen J, Kaskinoro K, Peltonen JE, Borra R, Lindroos MM, et al. Comparison of exogenous adenosine and voluntary exercise on human skeletal muscle perfusion and perfusion heterogeneity. J Appl Physiol 2010; 108: 378-386.

18. Heinonen IH, Kemppainen J, Kaskinoro K, Peltonen JE, Borra R, Lindroos M, et al. Regulation of human skeletal muscle perfusion and its heterogeneity during exercise in moderate hypoxia. Am J Physiol Regul Integr Comp Physiol 2010; 299: R72-R79.

19. Heinonen I, Wendelin-Saarenhovi M, Kaskinoro K, Knuuti J, Scheinin M, Kalliokoski KK. Inhibition of alpha-adrenergic tone disturbs the distribution of blood flow in the exercising human limb. Am J Physiol Heart Circ Physiol 2013; 305: H163-H172.

20. Heinonen I, Kemppainen J, Kaskinoro K, Langberg H, Knuuti J, Boushel R, et al. Bone blood flow and metabolism in humans: Effect of muscular exercise and other physiological perturbations. J Bone Miner Res 2013; 28: $1068-1074$.

21. Simmons GH, Minson CT, Cracowski JL, Halliwill JR. Systemic hypoxia causes cutaneous vasodilation in healthy humans. J Appl Physiol 2007; 103: 608-615.

22. Romijn JA, Coyle EF, Sidossis LS, Gastaldelli A, Horowitz JF, Endert E, et al. Regulation of endogenous fat and carbohydrate metabolism in relation to exercise intensity and duration. Am J Physiol 1993; 265: E380-E391.

23. Layden JD, Patterson MJ, Nimmo MA. Effects of reduced ambient temperature on fat utilization during submaximal exercise. Med Sci Sports Exerc 2002; 34: 774-779.

24. Davis RT III, Stabley JN, Dominguez JM 2nd, Ramsey MW, McCullough DJ, Lesniewski LA, et al. Differential effects of aging and exercise on intra-abdominal adipose arteriolar function and blood flow regulation. J Appl Physiol 2013; 114: 808-815.

25. Ramsey MW, Behnke BJ, Prisby RD, Delp MD. Effects of aging on adipose resistance artery vasoconstriction: Possible implications for orthostatic blood pressure regulation. J Appl Physiol 2007; 103: $1636-1643$.

26. Stallknecht B, Lorentsen J, Enevoldsen LH, Bülow J, Biering-Sørensen $\mathrm{F}$, Galbo $\mathrm{H}$, et al. Role of the sympathoadrenergic system in adipose tissue metabolism during exercise in humans. $J$ Physiol 2001; 536: 283-294.

27. Chan CK, Mak J, Gao Y, Man RY, Vanhoutte PM. Endotheliumderived NO, but not cyclic GMP, is required for hypoxic augmentation in isolated porcine coronary arteries. Am J Physiol Heart Circ Physiol 2011; 301: H2313-H2321.

28. Graser T, Vanhoutte PM. Hypoxic contraction of canine coronary arteries: Role of endothelium and cGMP. Am J Physiol 1991; 261: H1769-H1777.

29. Swift DL, Lavie CJ, Johannsen NM, Arena R, Earnest CP, O'Keefe $\mathrm{JH}$, et al. Physical activity, cardiorespiratory fitness, and exercise training in primary and secondary coronary prevention. Circ J 2013; 77: $281-292$. 